Jordi Bosch $\cdot$ Javier Retana $\cdot$ Xim Cerdá

\title{
Flowering phenology, floral traits and pollinator composition in a herbaceous Mediterranean plant community
}

\begin{abstract}
The relationships between flowering plants and their insect visitors were studied in a Mediterranean grassland in north-east Spain. Floral traits (size, shape, symmetry, and colour), floral rewards (pollen and nectar), flowering period, and floral visitors were recorded for the 17 most abundant plants in the community. Flowering was year-round, but most species flowered in spring. The three species that flowered after spring had small flowers, but the distribution of floral features (including rewards offered) did not show a strong seasonality. Ants contributed $58.5 \%$ to the flower visits recorded. Other frequent visitors were beetles $(12 \%)$, flies $(9.5 \%)$, honey bees $(6.4 \%)$, wild bees $(6.4 \%)$, and wasps (5.2\%). Honey bees were most abundant in April, wild bees from April to July, beetles from May to July, and ants from May to September. The lack of tight plantinsect associations was the rule, with most plant species visited by a rather diverse array of insects representing two or more orders. The plant species having narrower spectra of visitors either had flower rewards exposed or attracted mostly illegitimate visitors. By means of correspondence analysis four categories of plants were defined according to their main groups of visitors: (1) honey bees and large wild bees; (2) large wild bees; (3) ants and beetles; and (4) beetles and small-sized bees. The Mantel test was used to calculate correlations among four matrices representing similarities in visitors attracted, floral morphological traits, pollen-nectar rewards, and blooming time, respectively. In spite of seasonality shown by the different insect groups, results
\end{abstract}

\footnotetext{
J. Bosch

Bee Biology and Systematics Laboratory, USDA-ARS,

Utah State University, Logan, UT 84322-5310, USA

J. Retana $(\bowtie)$

Unidad de Ecología y CREAF, Facultad de Ciencias, Universidad Autónoma de Barcelona, E-08193 Bellaterra (Barcelona), Spain fax: (34 3) 58113 12; e-mail: Retana@cc.uab.es

X. Cerdá

Unidad de Ecología Evolutiva, Estación Biológica de Doñana, CSIC, Apdo. 1056, E-41080 Sevilla, Spain
}

indicate that the observed patterns of visitor distribution among plants were most affected by pollen-nectar rewards.

Key words Plant community $\cdot$ Flower visitors $\cdot$ Flowering periods $\cdot$ Flower traits $\cdot$ Flower rewards

\section{Introduction}

The spectra of visitors to flowering plants in a particular area are determined by many factors, the most obvious of which is the overlap between the flowering periods of each species and the activity periods of the anthophiles in that area. Given this overlap, each plant species presents particular morphological and physiological characteristics that can attract certain groups of floral visitors over others. Traditionally, this differential flower attractiveness has been given major importance in interpreting why particular visitors are observed on particular flowers and this has led to the establishment of "pollination syndromes" (based on flower colour, shape, odour, rewards and breeding systems), supposedly adapted to specific types of pollinators (Faegri and van der Pijl 1966). More recent anthecological studies have emphasised the relationship between energetics of flower visitors and floral rewards (Heinrich and Raven 1972; Heinrich 1975). Under this approach, flower rewards may be considered as the ultimate "attractants", whereas colour, odour and shape would act rather as "cues" used by visitors to discriminate between the different reward sources available (Waser 1983a). Many studies have confirmed the importance of nectar and/or pollen offered by flowers in determining how available anthophiles are partitioned between available flowering plants (e.g. Heinrich 1975; Tepedino and Parker 1982; Bosch 1992). As pointed out by Waser (1983a), however, pollinators with similar energetic or nutritional requirements have been shown to visit flower species offering a very wide range of rewards, and the same plant species may receive quite different visitor assemblages 
depending on the year (Tepedino and Stanton 1981; C.M. Herrera 1988), the habitat conditions (Primack 1978; Arroyo et al. 1982; C.M. Herrera 1988), or even the individuals sampled within a same site and year (C.M. Herrera 1988; Ashman and Stanton 1991). Competition and facilitation between plants for visitors (reviews in Pleasants 1983; Rathcke 1983; Waser 1983b), and competition for flowers between insects (Morse 1977; Inouye 1978, Pleasants 1981) have been shown to influence visitor distribution among flowers. While being always ultimately related to the energetic trade-offs between flowers and their visitors, these phenomena have emphasised the need to study whole plant communities to fully understand plant-pollinator interactions in an ecologically realistic situation.

The number of studies following the community approach is increasing, but available information is fragmentary at best. As far as Mediterranean ecosystems are concerned, our knowledge is restricted to woody communities (J. Herrera 1988; McCall and Primack 1992; Dafni and O'Toole 1994; J. Bosch and A. Bonet, unpublished work). Moreover, the majority of communitylevel anthecological studies are basically descriptive, with few attempts made (e.g. McCall and Primack 1992; J. Herrera 1988; Petanidou and Vokou 1993) to quantitatively evaluate the importance of the different factors involved in determining anthophile distribution among plants. In this study, we describe the insect-flower relationships in a herbaceous community of ruderal plants on the Spanish Mediterranean coast, and we examine the importance of time of bloom, morphological flower traits (shape, size and colour) and rewards offered by the plants (pollen and nectar) in determining the spectra of visitors monitored.

\section{Materials and methods}

Study area

The study area site $\left(c .2000 \mathrm{~m}^{2}\right)$ is located in Canet de Mar (Barcelona, north-east Spain) $\left(41^{\circ} 25^{\prime} \mathrm{N}, 23^{\circ} 7^{\prime} \mathrm{E}\right)$ at $50 \mathrm{~m}$ above sea level and $750 \mathrm{~m}$ inland. The climate is Mediterranean with a strong sea influence. Mean annual temperature is $16.1^{\circ} \mathrm{C}$, with January being the coldest month (mean: $8.5^{\circ} \mathrm{C}$ ) and July the hottest (mean: $24.1^{\circ} \mathrm{C}$ ). Mean annual precipitation is $757 \mathrm{~mm}$, of which $195 \mathrm{~mm}$ accumulate during the spring and $277 \mathrm{~mm}$ in autumn. July is the driest month, but there is no severe summer drought.

The community studied is a savannah-like grassland (Hyparrhenietum hirto-pubescentis), one of the most disturbed communities of the holm oak grove coastal ecosystem (Folch 1986). Two herbaceous layers may be distinguished: the upper layer (0.5-1 m high, $70-90 \%$ of total cover) is dominated by Hyparrhenia hirta, which gives the area a savannah-like appearance; the lower layer (15-30 m high, $30-40 \%$ of total cover) is dominated by Brachypodium retusum. It is considered a thermophilous rather than xerophilous community, since it is usually found in coastal and other sunny places of subhumid areas, but not in arid zones.

Floral morphology and rewards

We studied the 17 most common entomophilous plant species in the area. For each species studied, the colour of the corolla, its morphology, and the type of symmetry were recorded. Flower forms were referred to those of Faegri and van der Pijl (1966). The number of flowers per inflorescence and the size (maximum transversal diameter) of flowers and/or inflorescence (pollination units sensu Faegri and van der Pijl, 1966) was measured in samples of twenty pollination units for each plant species.

To investigate floral rewards, 20 flowers of each plant species were covered with fine mesh gauze bags to exclude insects. Twentyfour hours after the flowers opened, the mesh bags were removed and accumulated nectar was extracted with micropipettes $(0.25,0.5$, 1,2 , and $5 \mathrm{ml}$ ). About-to-dehisce anthers of each plant species were collected, placed in small Petri dishes and allowed to dry until they dehisced to fully expose their pollen. Anther tissues were separated carefully and pollen production was estimated by weighing (to the nearest $0.01 \mathrm{mg}$ ) the total amount of pollen in ten groups of fresh anthers from five to ten flowers (depending on plant species).

Flowering phenology and insect censuses

Three 25-m-long transects were laid across the study area, from April to October 1986. To determine flowering periods, the number of pollination units with open flowers of each plant species was counted at every transect once every other week.

On each sampling day, insect counts were made from 8.00 a.m. to 8.00 p.m. by slowly walking the transects every $2 \mathrm{~h}$. All insects observed foraging on the flowers within $1 \mathrm{~m}$ either side of the transect were identified by sight and recorded. For a few plant species poorly represented in the transects, additional plants were sampled to obtain comparative data of insect visits. Bees were visually determined to genus, and grouped in four categories: smallsized bees (body length $<8 \mathrm{~mm}$, including species of Ceratina, Andrena, Lasioglossum, and Hylaeus), medium-sized bees (body length 8-12 mm, including species of Osmia, Panurgus, Halictus, Megachile, Sphecodes, Colletes, Heliophila and Crocisa), largesized bees (body length $>12 \mathrm{~mm}$, including species of Bombus, Xylocopa, Melitturga, Eucera, Amegilla, Anthophora and Anthidium), and honey bees (Apis mellifera). Non-apoid visitors were determined to family level. Data for each plant were summarised by summing the number of floral visitors over all sampling dates and pollination units.

Data analysis

The spectra of flower visitors of each plant species were processed using correspondence analysis to generate a smaller number of factors from the original variables (insect groups), which better explained the dispersion of the data (ter Braak 1987). From the coordinates of the first axes obtained at the correspondence analysis, plants were grouped into classes of pollinator assemblages by cluster hierarchical methods.

To investigate the relative importance of floral morphology, floral rewards and time of flowering of each plant species in determining what insects go to what plants, four different matrices (named INSECTS, MORPHOLOGY, REWARDS and PHENOLOGY) were constructed. The elements of the INSECTS matrix were the proportional similarity indexes of insect spectra between each pair of plant species. The proportional similarity index (Colwell and Futuyma 1971) was calculated as: PS $=1-0.5$ $\left(\sum 1 i p_{\text {ix }}-p_{\text {iy }} l\right)$, where $p_{\text {ix }}$ and $p_{\text {iy }}$ were the proportions of each insect group $i$ on the insect spectra of plant $x$ and plant $y$, respectively. The elements of the MORPHOLOGY matrix were the proportions of the five floral features considered (colour, flower form, inflorescence type, size of the pollination unit, and number of flowers per pollination unit) that each pair of species had in common. The REWARDS matrix measured the dissimilarity of flower rewards produced by each pair of species. The absolute amounts of both nectar and pollen produced by flowers of each plant species were converted in proportions by dividing specific values by the maximum value (of nectar or pollen) produced by any species of the community. Then, the difference of pollen proportions of each 
pair of species was calculated, as well as the difference of nectar proportions. The sum of these two values was considered a measure of dissimilarity in floral rewards between species. In the PHENOLOGY matrix, the elements were the numbers of weeks between the flowering peaks of each pair of plants.

To develop an easier interpretation of results obtained, the REWARDS and PHENOLOGY matrices were transformed into similarity matrices with the SIMIL program of the $\mathrm{R}$ package (Legendre and Vaudor 1991). The correlation between the INSECTS matrix and each of the three other matrices was estimated by computing the Mantel test, also with the R package. A positive standardised Mantel $r$ value between the INSECTS matrix and the MORPHOLOGY matrix, for instance, would indicate that plants with similar insect spectra had similar floral morphologies, and plants with different insect spectra had different floral morphologies. Non-significant $r$ values would indicate that the relationship between insect visitors attracted and floral morphology was weak.

\section{Results}

Floral morphology and rewards

The main flower characteristics of the plant species studied are summarised in Table 1. The 17 species considered belong to eight families, of which only the Fabaceae and the Asteraceae are represented by more than two species. Five species of plants produced solitary flowers. The 12 remaining species produced lax (e.g. the two Cruciferae) to well-structured, compact (e.g. the Asteraceae) inflorescences. The size and number of open flowers of these inflorescences varied from those measuring circa $15 \mathrm{~mm}$ diameter and having fewer than ten flowers (Lobularia maritima, and Brassica fruticulosa) to the large umbella of Daucus carota $(67 \mathrm{~mm}$ diameter, and 1092 flowers). Of the 17 species, 7 had dish-bowltype readily accessible flowers, while the rest had somewhat restrictive flowers [6 with tubular corollas, and 4 (the legumes) with papilionaceous corollas]. The most common flower colours were yellow (seven species), purple (four species) and red (three species).

Eleven plant species produced nectar in extractable amounts (Table 2). Three of the four legumes produced the highest volumes of nectar per flower, but other species produced higher nectar volumes per inflorescence (e.g. D. carota, Sedum sediforme or Scabiosa atropurpurea). Nine species produced more than $0.1 \mathrm{~g}$ of pollen per flower (Table 2). The two species with the highest pollen production per flower (Papaver rhoeas and Ononis natrix) produced little or no nectar, although other species (e.g. the two Lathyrus species and Psoralea bituminosa) produced high amounts of both nectar and pollen.

Flowering phenology and density

The flowering phenology of the plant community is shown in Fig. 1. There was an extensive overlap of flowering periods from late April to June. Nine species were in bloom in April, but only two of these (Lathyrus latifolius and L. clymenum) reached peak bloom during that month. As many as 11 species flowered in synchrony during May-June, although many of them were not abundant (Table 1). Of the three summer-flowering species, D. carota, Sedum sediforme and Foeniculum vulgare, only the latter remained in flower in August and September. From September to late February only L. maritima was in bloom. Duration of flowering was variable and not related to the season of the year in which plants flowered (Fig. 1). The shortest flowering periods were those of $S$. sediforme (1 month), and L. latifolius, L. clymenum and P. rhoeas (1.5 months). Other plants flowered for much longer periods: $F$. vulgare and Euphorbia segetalis (4 months), B. fruticulosa (5 months), and Lobularia maritima (9 months). Flowers of three species (Lathyrus maritima, L. latifolius and $F$. vulgare) largely out-numbered other entomophilous species during periods of peak bloom. All other species did not reach 15 pollination units $/ \mathrm{m}^{2}$ at any time of the season (Table 1).

\section{Seasonal patterns and spectra of insect visitors}

The relative abundance of insect visitors throughout the season is outlined in Table 3. The honey bee, Apis mellifera, was by far the most abundant flower visitor in April, during the flowering period of L. latifolius and L. clymenum (two abundant species producing large amounts of nectar, Table 2). Its numbers then rapidly declined, and ants and beetles (mainly Mordellidae, Dasytidae, Scarabaeidae and Bruchidae) were the predominant groups from May to July (when the highest number of plant species were in bloom). The summer period (coinciding with $F$. vulgare flowering) was characterised by a decrease in the activity of all insect groups except ants, that made up to $85 \%$ of the visits recorded. Finally, in September-October, with the decline of F. vulgare and the beginning of L. maritima bloom, dipterans (Syrphidae, Bombyliidae, Calliphoridae, Muscidae) and wasps were the most abundant anthophilous groups.

The spectra of insect visitors to the plant species studied are shown in Table 4. By means of ordination and classification analyses, we established different groups of plants according to the insects that visited their flowers. The two first axes of the correspondence analysis explained $47.6 \%$ of the total variance of data. Four categories of plants were defined (Fig. 2). The first category included three plant species whose main flower visitors were $A$. mellifera and, to a lesser extent, other large-sized bees. These three plant species produce large amounts of nectar. Considering the whole community, a significant positive correlation $(r=0.79, P=0.001)$ was found between the percentage of A. mellifera and other large-sized-bee visitation, and the average volume of nectar produced per flower. The second group was composed of plant species mainly visited by large-sized bees, and by honey bees and/or ants. The third cate- 


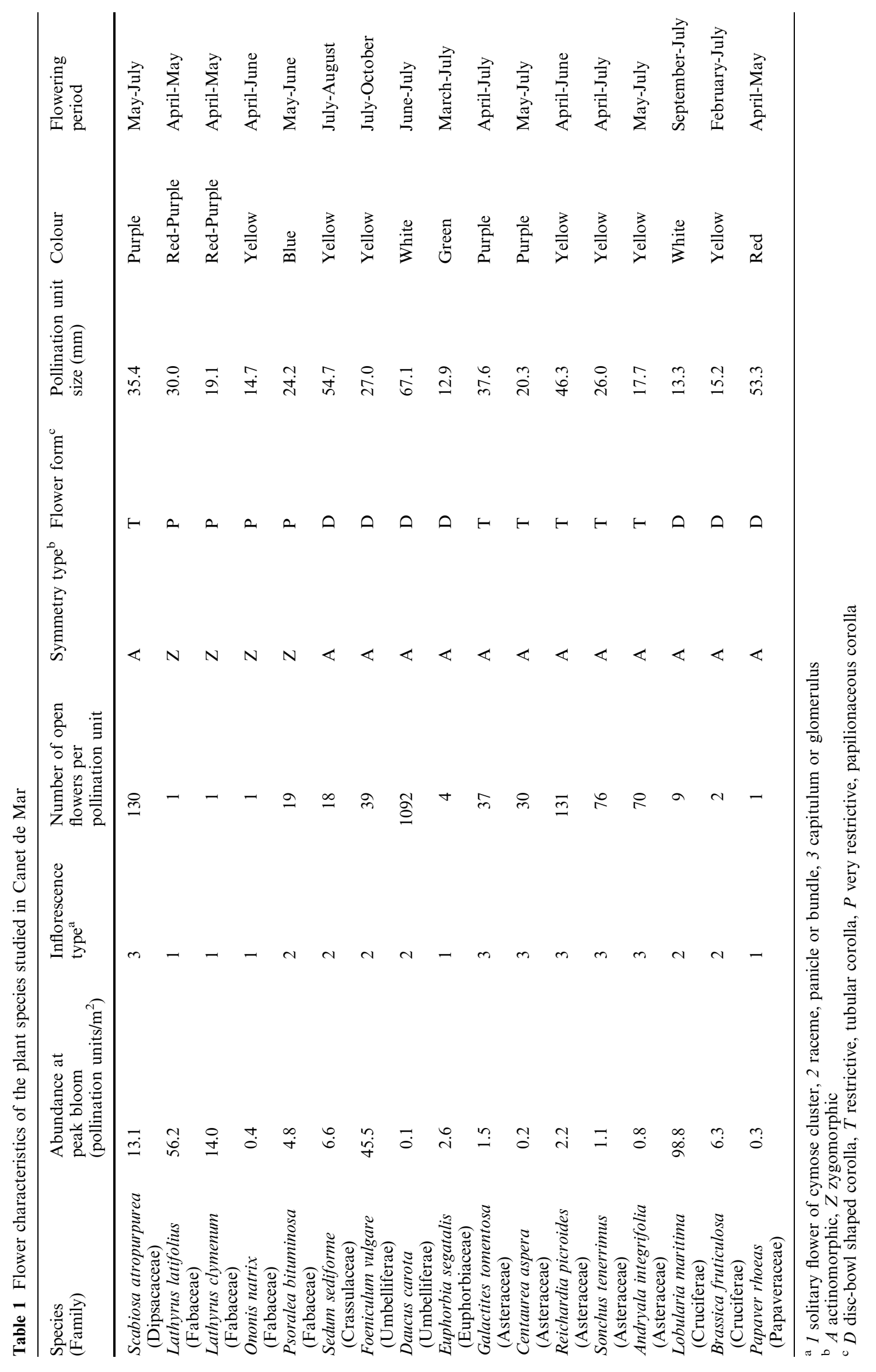


Table 2 Rewards (total pollen production and nectar accumulated for $24 \mathrm{~h}$ ) per flower and per pollination unit of the plant species studied. Mean \pm SE is indicated. A hyphen (-) indicates unmeasurable or no nectar production

\begin{tabular}{llccc}
\hline Species & $\begin{array}{l}\text { Nectar per } \\
\text { flower }(\mu \mathrm{l})\end{array}$ & $\begin{array}{l}\text { Nectar per } \\
\text { pollination unit }(\mu \mathrm{l})\end{array}$ & $\begin{array}{l}\text { Pollen per } \\
\text { flower }(\mathrm{mg})\end{array}$ & $\begin{array}{l}\text { Pollen per } \\
\text { pollination unit }(\mathrm{mg})\end{array}$ \\
\hline Scabiosa atropurpurea & 0.06 & 7.78 & 0.070 & 9.100 \\
Lathyrus latifolius & 0.66 & 0.66 & 0.358 & 0.358 \\
Lathyrus clymenum & 0.49 & - & 0.265 & 0.265 \\
Ononis natrix & - & 9.96 & 0.516 & 0.516 \\
Psoralea bituminosa & 0.53 & 8.75 & 0.212 & 4.028 \\
Sedum sediforme & 0.16 & 7.02 & 0.254 & 4.572 \\
Foeniculum vulgare & 0.18 & 21.84 & 0.039 & 1.521 \\
Daucus carota & 0.02 & 0.28 & 0.026 & 28.392 \\
Euphorbia segetalis & 0.07 & 2.22 & 0.012 & 0.048 \\
Galactites tomentosa & 0.06 & -3.91 & 0.092 & 3.404 \\
Centaurea aspera & 0.13 & - & 0.170 & 5.100 \\
Reichardia picroides & - & - & 0.107 & 14.017 \\
Sonchus tenerrimus & - & - & 0.025 & 1.900 \\
Andryala integrifolia & - & 0.13 & 0.018 & 1.610 \\
Lobularia maritima & - & - & 0.151 & 0.162 \\
Brassica fruticulosa & 0.06 & 11.240 & 0.302 \\
Papaver rhoeas & - & & & 11.240 \\
\hline
\end{tabular}

Fig. 1 Flowering periods of the main entomophilous plant species (for details see Fig. 2) in the grassland of Canet de Mar. The vertical lines indicate the blooming peaks

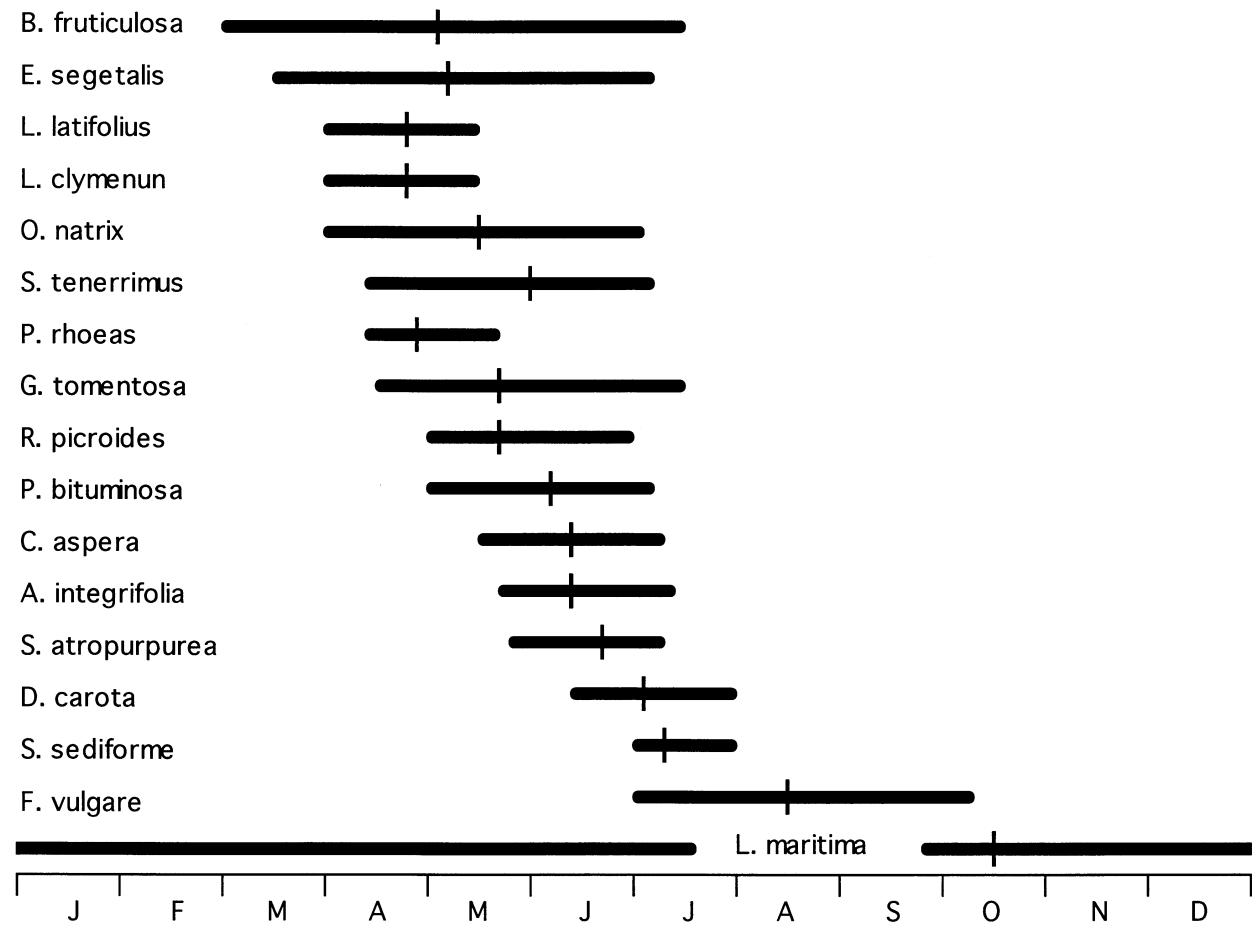

gory of plants included species mostly visited by ants (although mordellids were the dominant visitors of D. carota). The fourth category included the remaining six plant species, characterised by a wide spectrum of visitors including small bees, ants, beetles, dipterans, butterflies and mirid bugs.

The importance of flower features (morphology, rewards, and bloom time) in determining the composition of the visitor spectrum of each plant has been analysed by assessing the correlation between the matrix of similarity of insect spectra (INSECTS) and the three matrices of similarity of plant features (REWARDS,
MORPHOLOGY and PHENOLOGY). The results reveal that floral rewards had a highly significant effect on insect spectra (Mantel standardised statistic between REWARDS and INSECTS is $r=0.422, P<0.01$ ), floral morphology had a lower, but significant effect ( $r=0.205, P<0.05)$, and blooming time had no effect on determining the array of flower visitors that a plant would receive $(r=0.019, P>0.3)$. Morphological traits and rewards were more strongly correlated $(r=0.20$, $P<0.05)$, than was either with flowering time (MORPHOLOGY-PHENOLOGY: $r=0.17, P=0.05$; REWARDS-PHENOLOGY: $r=0.02, P>0.4$ ). 
Table 3 Percentage of the main groups of insect visitors recorded at the transects throughtout the year ( $N$ number of insects censussed each month)

\begin{tabular}{|c|c|c|c|c|c|c|c|c|}
\hline Groups of insects & Overall & April & May & June & July & August & September & October \\
\hline Ants & 58.5 & 1.3 & 37.5 & 30.4 & 29.8 & 85.8 & 73.7 & 7.8 \\
\hline Honey bees & 6.4 & 70.4 & 0.0 & 8.0 & 7.5 & 0.0 & 0.2 & 7.8 \\
\hline Large-sized bees & 2.7 & 4.7 & 1.9 & 8.0 & 10.9 & 0.0 & 0.0 & 0.0 \\
\hline Medium-sized bees & 1.2 & 2.0 & 1.5 & 2.5 & 4.0 & 0.2 & 0.0 & 0.0 \\
\hline Small-sized bees & 2.5 & 5.4 & 8.3 & 2.5 & 4.3 & 1.2 & 0.0 & 0.0 \\
\hline Other Hymenopterans & 5.2 & 0.7 & 1.5 & 4.2 & 5.8 & 5.8 & 6.4 & 17.7 \\
\hline Coleopterans & 12.0 & 3.4 & 40.2 & 21.5 & 33.1 & 1.1 & 2.0 & 2.0 \\
\hline Dipterans & 9.5 & 12.1 & 9.1 & 6.8 & 3.0 & 5.8 & 17.2 & 60.8 \\
\hline Lepidopterans & 0.5 & 0.0 & 0.0 & 1.3 & 1.1 & 0.1 & 0.5 & 3.9 \\
\hline Heteropterans & 1.5 & 0.0 & 0.0 & 14.8 & 0.5 & 0.0 & 0.0 & 0.0 \\
\hline$n$ & 3,615 & 224 & 396 & 355 & 488 & 1420 & 656 & 76 \\
\hline
\end{tabular}

Table 4 Percentages of insect visitors recorded on the flowers of the plant species studied ( $N$ total number of insects recorded on each plant species; for abbreviations of plant species and flower visitors, see Fig. 2)

\begin{tabular}{|c|c|c|c|c|c|c|c|c|c|c|c|c|c|c|c|}
\hline Species & $\mathrm{N}$ & Apis & Labe & Mebe & Smbe & Ants & Hyme & Mord & Oede & Bruc & Cole & Sirp & Dipt & Lepi & Hete \\
\hline Satr & 233 & 42.9 & 9.9 & 3.9 & 4.7 & 8.2 & 1.3 & 2.1 & 10.6 & 5.6 & & 0.9 & 3.9 & 6.0 & \\
\hline Llat & 114 & 86.0 & 7.0 & & & 7.0 & & & & & & & & & \\
\hline Lcly & 44 & 90.9 & 9.1 & & & & & & & & & & & & \\
\hline Onat & 52 & & 30.8 & 9.7 & 3.8 & 30.8 & 11.5 & & & 1.9 & 11.5 & & & & \\
\hline Pvit & 100 & 12.0 & 31.0 & 1.0 & 1.0 & 46.0 & 3.0 & & 2.0 & & 3.0 & & & & 1.0 \\
\hline Seed & 106 & 19.8 & 38.7 & 13.2 & & 4.7 & 11.3 & 10.4 & & & & & 1.9 & & \\
\hline Fvul & 1454 & & & 0.8 & 2.8 & 77.5 & 5.8 & 6.3 & & 0.3 & 0.1 & 2.1 & 4.3 & & \\
\hline Dcar & 567 & & & & 0.7 & 28.6 & & 0.4 & 67.7 & & 0.5 & 0.9 & & 1.2 & \\
\hline Eseg & 108 & & & & 2.8 & 65.7 & 7.4 & 0.9 & 0.9 & & 10.3 & 4.6 & 7.4 & & \\
\hline Glom & 145 & 13.8 & & 4.8 & 2.0 & 53.1 & & 0.7 & 12.4 & 2.8 & 9.7 & 0.7 & & & \\
\hline Casp & 108 & 25.9 & 1.9 & 13.9 & 2.8 & 29.6 & & 4.6 & 6.5 & 2.8 & 3.7 & & & & 8.3 \\
\hline Rpic & 50 & & & 4.0 & 26.0 & 2.0 & 6.0 & 8.0 & 10 & 2.0 & 38.0 & & 2.0 & 2.0 & \\
\hline Sten & 60 & 6.7 & & 5.0 & 23.3 & 11.7 & & 8.3 & 6.7 & 5.0 & 10.0 & 3.3 & 10.0 & & 10.0 \\
\hline Aint & 116 & 4.3 & & 7.8 & 21.6 & 0.9 & & 10.3 & 12.9 & 2.6 & 10.3 & 4.3 & & 0.9 & 24.1 \\
\hline Amar & 133 & 0.7 & & 0.7 & 6.0 & 7.5 & 2.3 & 14.3 & 5.3 & 14.3 & 15.8 & 3.8 & 26.3 & 3.0 & \\
\hline Bfru & 106 & 9.4 & & 1.9 & 35.0 & 7.5 & 0.9 & 1.9 & 1.9 & 1.9 & 9.4 & 24.6 & 4.7 & 0.9 & \\
\hline Prho & 40 & 5.0 & 2.5 & 2.5 & 5.0 & & & & 57.5 & & 27.5 & & & & \\
\hline
\end{tabular}

\section{Discussion}

As with other Mediterranean entomophilous plant communities, the savannah-like grassland of Canet de Mar is characterised by an abundance of species flowering in spring and a scarcity of plants flowering throughout the rest of the year. While in some of these communities flowering is interrupted during the summer-drought period (Arroyo 1990; Petanidou et al. 1995; J. Bosch and A. Bonet, unpublished work), or during the cold winter period at high elevations (Arroyo 1990), in those at low elevations it encompasses the whole year (J. Herrera 1986; Arroyo 1990; and this study). The flower composition of the community studied is dominated by a few very abundant species (the two Lathyrus species in early spring, $S$. atropurpurea in late spring, $F$. vulgare in summer, and L. maritima in autumn and winter), while the remaining species are much scarcer and their contribution to the flower density of the study area is, in some cases, almost testimonial.
The flower types (characterised by shape, inflorescence arrangement, size, colour, and rewards) were diverse and more or less evenly distributed throughout the year, as indicated by the results of the Mantel test. However, all plants not flowering during spring ( D. carota, S. sediforme, F. vulgare and L. maritima) had small, readily accessible flowers. A similar decrease in flower size has been reported for several plant families in Israel, and has been indicated to reflect a transition from a situation of surplus flowers available to pollinators (spring) to a situation of surplus pollinators available to flowers (summer) in which investment on large flower advertisement would not be compensated by increased pollinator service (Shmida and Dafni 1989; Shmida and Dukas 1990).

Ants were the dominant flower-visiting insect group in the Canet grassland. They were found in all but two of the 17 plant species studied, and accounted for more than $10 \%$ of the visits to 8 species. At least in some cases, they behaved as legitimate visitors, thus supporting the 


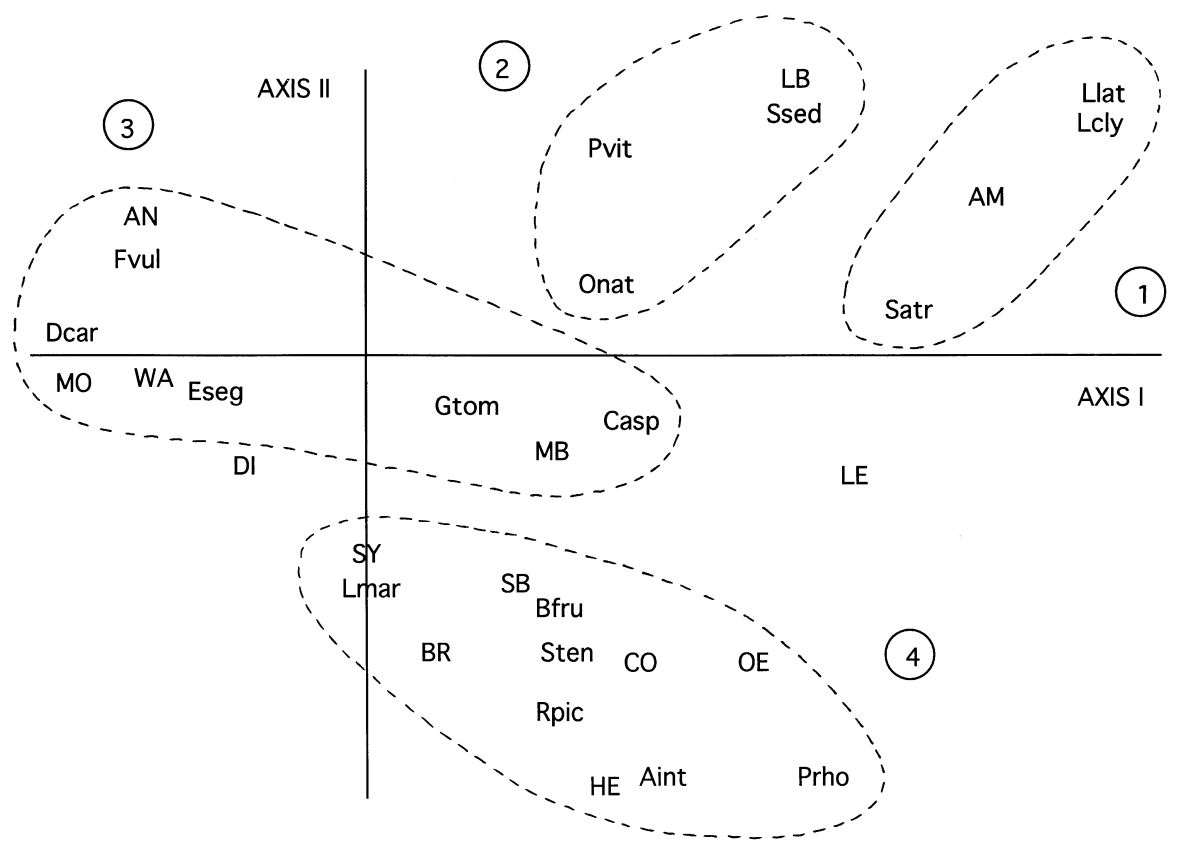

Fig. 2 Representation of plant species and flower visitors of the community of Canet de Mar in the first two axes obtained in the correspondence analysis. Broken lines enclose the individuals of the four groups ( 1 to 4 ) defined with automatic classification methods. Abbreviations of plant species: Ll (Lathyrus lathifolius), Lc (L. clymenum), Sa (Scabiosa atropurpurea), Pb (Psoralea bituminosa), On (Ononis natrix), Ss (Sedum sediforme), Fv (Foeniculum vulgare), Dc (Daucus carota), Es (Euphorbia segetalis), Gt (Galactites tomentosa), $\mathrm{Ca}$ (Centaurea aspera), Rp (Reicardia picripes), St (Sonchus tenerrimus), Ai (Andryalia integrifolia), Lm (Lobularia maritima), Bf (Brassica fruticulosa), Pr (Papaver rhoeas). Abbreviations of flower visitors: AM (Apis mellifera), LB (other large bees), MB (medium-sized bees), SB (small bees), AN (ants), WA (wasps), MO (Mordellids), OE (Oedemerids), BR (Bruchids), CO (other coleopterans), SY (syrphids), DI (other dipterans), LE (lepidopterans), HE (Heteropterans)

notion that ants can be important pollinators in certain ecosystems (Hickman 1974; Gómez and Zamora 1992; Gómez et al. 1996). Bees, beetles and dipterans followed in importance as floral visitors. The abundance of honey bees (representing 50\% of the bees recorded) was probably the result of man-kept colonies. Despite the high diversity of wild bees and their importance as pollinators in Mediterranean ecosystems (Michener 1979; Petanidou and Ellis 1993; Dafni and O’Toole 1994), other groups of anthophiles [especially beetles and dipterans (J. Herrera 1988; J. Bosch and A. Bonet, unpublished work), but also ants in this study] sometimes out-number them as flower visitors in such ecosystems. In this study, wasps were nearly as frequent visitors as wild bees. Other reputedly specialised groups of flower-visitors were rare (butterflies) or absent (hawk moths and birds). Thus, the anthophile assemblage in the grassland of Canet de Mar was dominated by groups of insects traditionally viewed as rather unspecialized flower visitors.

Another characteristic of the community studied is the scarcity of narrow insect-flower associations, with most plant species being visited by a diverse array of insects representing two to three orders. These results agree with those reported for other temperate communities (Pojar 1974; Small 1976; Primack 1978, 1983; O’Brien 1980; Motten 1986; J. Herrera 1988; Inouye and Pyke 1988; McCall and Primack 1992), while most plants in a coastal scrub in Southeast Jamaica were visited by only one to two orders of insects (Percival 1974). The relative scarcity of complicated flower morphologies that might hinder visitation by certain insect groups, and the fact that even some of the reputedly restrictive corollas (papilionaceous and narrowly tubular) received visits by an ample spectrum of anthophilous insects (including some traditionally considered typical of open flowers, such as ants, beetles or bugs) help explain the wide spectra of visitors observed in this study. Actually, most of the species with relatively narrow visitor spectra $(F$. vulgare with $77.5 \%$ ants, $D$. carota with $67.7 \%$ mordellids, $E$. segetalis with $65.7 \%$ ants, and P. rhoeas with $85 \%$ beetles) have disc-bowl-shaped, readily accessible corollas. The two Lathyrus, with papilionaceous corollas, also had restricted visitor spectra, but their main visitor, the honey bee $(86 \%$ and $90.9 \%$ of their recorded visits, respectively), penetrated the flowers from the side without contacting the anthers or stigmas, while other apoids visited them legitimately. While in north-east Spain A. mellifera colonies are active for most of the year (late winter to late autumn, Bonet et al. 1985), honey bee foragers only appeared in great numbers in the study area early in the season on plants with high densities and high nectar productions (the two Lathyrus species and $S$. atropurpurea to some extent). The ability of honey bees to exploit the richest floral sources has been documented in several instances (e.g. Schaffer et al. 1979; Ginsberg 1983; Bosch 1992) and related to the high energetic demands of honey bee colonies and the capacity of workers to recruit nest 
mates to long-distance food sources (von Frisch 1967; Seeley 1985).

The scarcity of narrow associations does not preclude a certain structure in the plant-pollinator interactions of the community studied. The correspondence analyses clustered four groups of plants based on their main types of visitors. The next step was to evaluate the importance of different sets of plant characteristics (blooming time, floral morphological traits, and floral rewards) in determining the loose pattern of insect partitioning observed. Our results indicate that flowers with similar reward composition tended to attract similar groups of visitors. Thus, the distribution of insects among flowering plants in the Canet grassland was more dependent on the insect response to flower rewards than on the insect response to flower morphology. Flowering periods had the least effect on the types of pollinators attracted, in spite of the seasonality shown by some of the insect groups and as opposed to results obtained in two Spanish Mediterranean scrublands, where species flowering at about the same time tended to be visited by similar insects, irrespective of their floral features (J. Herrera 1988; J. Bosch and A. Bonet, unpublished work). In a phryganic ecosystem in Greece early-flowering Labiatae were visited by similar bee assemblages, while late-flowering Labiatae were not (Petanidou and Vokou 1993). Unlike most other flower-visiting insects, ants have long activity periods ( 7 months in the study area) and as a consequence they depend on a succession of flowering plant species for nectar resources, thus reducing the seasonal component of pollination relationships in the grassland. Of the two flower rewards, pollen and nectar, the latter undoubtedly plays a major role in determining antophile distribution in Canet, since more than $70 \%$ of the visitors attracted to flowers (including ants, wasps, butterflies and most honey bees) foraged only for nectar. Unfortunately, little is known about the relative importance of pollen and nectar in the diets of several flower-visiting coleopterous and dipterous taxa. Future studies emphasising the feeding habits of these insect groups and the possible correlations between pollen and/or nectar production and certain floral morphological traits would greatly improve our understanding of the importance of floral rewards and other floral characteristics in determining distribution of pollinators among plants.

Acknowledgements We are grateful to C.M. Herrera (CSIC, Sevilla, Spain) and to P.F. Torchio (USDA-ARS, Logan, Utah, USA) for reviewing and early draft of the manuscript. S. Durham (Utah State University, USA) provided statistical advice. This is a contribution from the Utah Agricultural Experiment Station, Utah State University, Logan, Utah, Journal Paper No. 4913.

\section{References}

Arroyo J (1990) Spatial distribution of flowering phenology in the Mediterranean shrublands of southern Spain. Isr J Bot 39: 249-262
Arroyo MTK, Primack RB, Armesto J (1982) Community studies in pollination ecology in the high temperate Andes of central Chile. I. Pollination mechanisms and altitudinal variation. Am J Bot 69:82-97

Ashman T-L, Stanton ML (1991) Seasonal variation in pollination dynamics of sexually dimorphic species, Sidalcea oregana spp. spicata (Malvaceae). Ecology 72:993-1003

Bonet A, Rita J, Sebastià MT (1985) La flora mel·lífera de la circumscripció de Barcelona. Servei d'Agricultura i Ramaderia de la Diputació de Barcelona, Barcelona

Bosch J (1992) Floral biology and pollinators of three co-occurring Cistus species (Cistaceae). Bot J Linn Soc 109:39-55

Braak CJF ter (1987) Ordination. In: Jongman RHG, Braak CJF ter, Tongeren OFR van (eds) Data analysis in community and landscape ecology. Pudoc, Wageningen, pp 91-173

Colwell RK, Futuyma DJ (1971) On the measurements of niche breadth and overlap. Ecology 52:567-576

Dafni A, O'Toole C (1994) Pollination syndromes in the Mediterranean: generalisations and peculiarities. In: Arianoutsou M, Groves RH (eds) Plant-animal interactions in Mediterraneantype ecosystems. Kluwer, Dordrecht, pp 125-135

Faegri K, Pijl L van der (1966) The principles of pollination ecology. Pergamon, Oxford

Folch R (1986) La vegetació dels pasos catalans. Ketrés, Barcelona

Frisch K von (1967) The dance language and orientation of bees. Harvard University Press, Cambridge

Ginsberg HS (1983) Foraging ecology of bees in an old field. Ecology 64:165-175

Gómez JM, Zamora R (1992) Pollination by ants: consequences of the quantitative effects on a mutualistic system. Oecologia $91: 410-418$

Gómez JM, Zamora R, Hodar JA, García D (1996) Experimental study of pollination by ants in Mediterranean high mountain and arid habitats. Oecologia 105:236-242.

Heinrich B (1975) Energetics of pollination. Annu Rev Ecol Syst 6:139-170

Heinrich B, Raven P (1972) Energetics and pollination ecology. Science 176:597-602

Herrera CM (1988) Variation in mutualisms: the spatio-temporal mosaic of a pollinator assemblage. Biol J Linn Soc $35: 95-125$

Herrera $\mathbf{J}$ (1986) Flowering and fruiting phenology in the coastal shrublands of Doñana, south Spain. Vegetatio 68:91-98

Herrera J (1988) Pollination relationships in southern Spanish Mediterranean shrublands. J Ecol 76:274-287

Hickman JC (1974) Pollination by ants: a low-energy system. Science 184:1290-1292

Inouye DW (1978) Resource partitioning in bumblebees: experimental studies of foraging behavior. Ecology 59:672-678

Inouye DW, Pyke GH (1988) Pollination biology in the Snowy Mountains of Australia: comparisons with montane Colorado, USA. Aust J Ecol 13:191-210

Legendre P, Vaudor A (1991) The R package: multidimensional analysis, spatial analysis. Departement de sciences biologiques, Université de Montreal, Quebec

McCall C, Primack RB (1992) Influence of flower characteristics, weather, time of day, and season on insect visitation rates in three plant communities. Am J Bot 79:434-442

Michener CD (1979) Biogeography of the bees. Ann Missouri Bot Gard 66:277-347

Morse D (1977) Resource partitioning in bumblebees: the role of behavioral factors. Science 197:678-679

Motten AF (1986) Pollination ecology of the spring wildflower community of a temperate deciduous forest. Ecol Monogr $56: 21-42$

O'Brien MH (1980) The pollination biology of a pavement plain: pollinator visitation patterns. Oecologia 47:213-218

Percival M (1974) Floral ecology of coastal scrub in southeast Jamaica. Biotropica 6:104-129

Petanidou T, Ellis WN (1993) Pollinating fauna of a phryganic ecosystem: composition and diversity. Biodiversity Lett 1:922 
Petanidou T, Ellis WN, Margaris NS, Vokou D (1995) Constraints on flowering phenology in a phryganic (east Mediterranean shrub) community. Am J Bot 82:607-620

Petanidou T, Vokou D (1993) Pollination ecology of Labiateae in a phryganic (east Mediterranean) ecosystem. Am J Bot 80:892899

Pleasants J (1981) Bumblebee response to variation in nectar availability. Ecology 62:1648-1661

Pleasants J (1983) Structure of plant and pollinator communities. In: Jones CE, Little RJ (eds) Handbook of experimental pollination biology. Van Nostrand Reinhold, New York, pp 375393

Pojar J (1974) Reproductive dynamics of four plant communities of southwestern British Columbia. Can J Bot 52:1819-1834

Primack RB (1978) Variability in New Zealand montane and alpine pollinator assemblages. N Z J Ecol 1:66-73

Primack RB (1983) Insect pollination in the New Zealand mountain flora. N Z J Bot 21:317-333

Rathcke B (1983) Competition and facilitation among plants for pollination. In: Real L (ed) Pollination biology. Academic Press, London, pp 305-329

Schaffer WM, Jensen DB, Hobbs DE, Gurevitch J, Todd JR, Schaffer MV (1979) Competition, foraging energetics, and the cost of sociality in three species of bees. Ecology 60:976-987
Seeley TD (1985) Honey bee ecology. Princeton University Press, Princeton

Shmida A, Dafni A (1989) Blooming strategies, flower size and advertising in the "lily-group" geophytes in Israel. Herbertia 45:111-123

Shmida A, Dukas R (1990) Progressive reduction in the mean body sizes of solitary bees active during the flowering season and its correlation with the sizes of the bee flowers of the mint family (Lamiaceae). Isr J Bot 89:133-141

Small E (1976) Insect pollinators of the Mer Bleue peat bog of Ottawa. Can Field-Nat 90:22-28

Tepedino VJ, Parker FD (1982) Interspecific differences in the relative importance of pollen and nectar to bee species foraging on sunflowers. Environ Entomol 11:246-250

Tepedino VJ, Stanton NL (1981) Diversity and competition in beeplant communities on short-grass prairie. Oikos 36:35-44

Waser NM (1983a) The adaptive nature of floral traits: ideas and evidence. In: Real L (ed) Pollination biology. Academic Press, London, pp 241-285

Waser NM (1983b) Competition for pollination and floral character differences among sympatric plant-species: a review of evidence. In: Jones CE, Little RJ (eds) Handbook of experimental pollination biology. Van Nostrand Reinhold, New York, pp 277-293 